\title{
ESTUDIO BIOSISTEMÁTICO DE LA FAMILIA FABACEAE DEL DISTRITO DE TORATA, MOQUEGUA
}

\author{
BIOSISTEMATIC STUDY OF FABACEAE FAMILY FROM \\ TORATA, MOQUEGUA
}

\author{
Rosa Amelia Caffo Marruffo \\ RESUMEN
}

\begin{abstract}
El trabajo pretende identificar y caracterizar las especies de la familia Fabaceae existentes en el distrito de Torata que se encuentra ubicado en la Provincia Mariscal Nieto, a $25 \mathrm{~km}$ de la ciudad de Moquegua, en una gradiente altitudinal de 2207 m.s.n.m. La metodología consistió en colecciones de campos de cultivo, caminos, laderas, montes ribereños y plazuela de la zona de estudio. La identificación se hizo mediante el uso de claves taxonómicas, visita a herbarios y entrevista a expertos. Se reporta 21 especies de la familia Fabaceae, perteneciente a 18 géneros y 3 sub-familias. La sub-familia Faboideae fue la mejor representada con 14 especies.
\end{abstract}

Palabrasclave:Fabáceas, biosistemática, taxonomía.

\section{ABSTRACT}

The study aimes to identify and characterize the species of family Fabaceae existing in Torata, a district located in Mariscal Nieto province, $25 \mathrm{~km}$ far from Moquegua city, in an altitudinal gradient of 2207 meters above sea level. The methodology consisted in collections offields, roads, slopes, riparian forests and the square in the study area.The identification was made by using taxonomic keys, visits to herbal houses and experts' interviews. We report 21 species of the family Fabaceae, belonging to 18 genera and 3 subfamilies. The subfamily Faboideae was the best represented with 14 species.

Keywords: Fabaceae, biosystematics, taxonomy

\section{I.- INTRODUCCIÓN}

La diversidad biológica del departamento de Moquegua ha sido poco estudiada, a pesar de ser conocida la importancia y urgencia de este tipo de trabajo con propósitos de conservación (Ferreyra, 1961; Rodríguez, 1996, citado por Mostacero 1993). Los primeros estudios florísticos fueron ejecutados por Ferreyra en las lomas de Ilo, posteriormente investigadores como Weberbauer; Dillon, R.; Vargas, C.; Núñez, E. realizaron colecciones de flora como parte de proyectos más amplios.

Una de las familias botánicas más importantes en la flora tropical es el de las leguminosas o Fabaceae. Esta familia incluye numerosas especies con una gran variedad de portes y formas de vida. Muchas de sus especies tienen una enorme importancia económica para el hombre (Heywood, 1995).
Las Fabáceas son una familia del Orden de las Fabales. Reúne árboles, arbustos y hierbas perennes o anuales.

Es una familia de distribución cosmopolita con aproximadamente 730 géneros y más de 12000 especies, datos que la convierte en la tercera familia con mayor riqueza de especies después de las compuestas (Asteráceas) y las orquídeas (Orchidaceae).

Son características de la familia:

- El tipo de hoja que, por lo general, es compuesta.

- La flor el perianto es doble y consta de un cáliz integrado por cinco sépalos más o menos soldados y de una corola con cinco pétalos libres, que presenta una morfología característica. 
- El fruto por lo general es vaina.

- Fija el nitrógeno en el suelo y ayuda a fortalecer la tierra de nutrientes, gracias a que en la raíz habita una bacteria llamada rizobio.

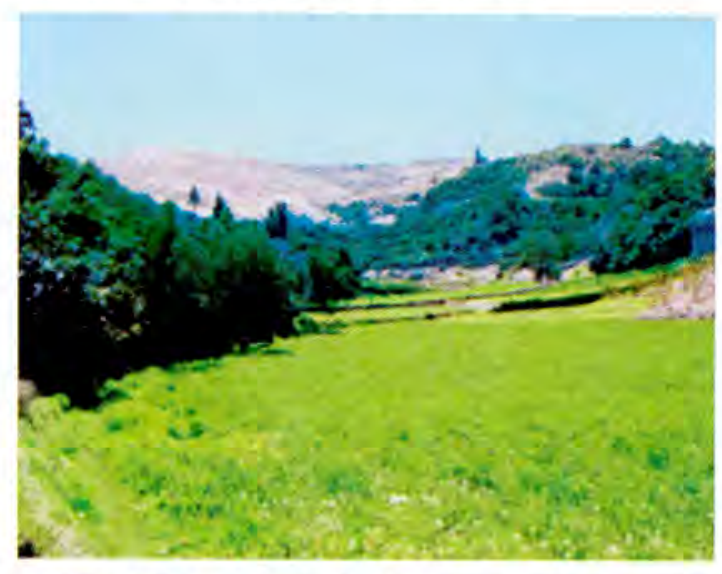

Gráfico $\mathrm{N}^{\circ} 01$. Paisaje del departamento de Tarata.

Según la concepción seguida por la mayor parte de taxónomos modernos, las leguminosas o fabáceas se clasifican en tres grupos ya sea como familias o sub-familias (Mostacero, 1993):

1.- Mimosoideae con flores actinomorfas, estas por lo general son pequeñas, tiene una corola de pre-floración valvar con numerosos estambres.

2.-Caesalpinoideae con flores zigomorfas, raramente sub-actinomorfas, tiene hojas no bipinnadas, corola generalmente de pre floración imbricada, ascendente, estandarte cubierto en sus bordes por otros pétalos, diez estambres libres.

3.-Faboideae con corola de pre floración imbricada descendente, el estandarte cubre las alas y la quilla, corola papilionada $\mathrm{y}$ estambres diadelfos.

Muchas de ellas tienen una gran significación económica como alimento humano (arveja, frejol, garbanzo, haba, lupino, maní, soya, entre otras); además de su significancia como calidad de alimento por su aporte de proteínas y carbohidratos a la dieta, también tiene uso forrajero (alfalfa, trébol, etc.), forestal (falsa acacia), medicinal (culén), industrial (soya, maní). Adicionalmente, un número importante de ellas se encuentran constituyendo malezas en cultivo (arvejilla, retamilla, entre otras).

En muchos países en desarrollo, las leguminosas son de importancia fundamental en la economía de la naturaleza y son, a veces, llamadas "la carne de los pobres" debido a su uso por muchas culturas como fuente primaria de proteína en su alimentación, por miles de años (Bruno, 1990).

Un estudio de distribución de las especies de esta familia es muy importante por cuanto permite, por un lado, reforzar la situación taxonómica de las especies, y por otro lado, conocer la ubicación de recursos vegetales, tanto para el uso directo, industrial, así como fuente de recursos filogenéticos.

El estudio biosistemático de las plantas genera conocimiento base sobre su biología, permite entender su fisiología, así como conocer en beneficios del género humano.

En este sentido, consideramos que se requiere complementar estudios de los recursos diversos del lugar, sobre todo en relación a la biología de cada una de las especies identificadas así como la sistemática de cada una de ellas, teniendo en cuenta que ha sido y sigue siendo afectada por diversas actividades humanas, y por fenómenos naturales. El objetivo de la presente investigación aportar al conocimiento el estudio biológico y taxonómico de las leguminosas en el distrito de Torata, departamento de Moquegua, Provincia Mariscal Nieto.

\section{OBJETIVO}

Determinar la biología y taxonomía de las especies de la familia Fabaceae.

\section{II.-MATERIALES Y MÉTODOS}

\subsection{Descripción}

El estudio es de carácter sustantivo descriptivo. No se emplea la clasificación de variables que alude a variable independiente y dependiente, ya que el estudio no establece relación de dependencia e independencia. Por lo tanto, son variables de estudio:

- Las características botánicas de cada una de las especies estudiadas.

- La taxonomía de las especies

Las muestras obtenidas fueron procesadas en el Laboratorio de Biología de la Facultad de Ciencias de la UNJBG.

\subsection{Metodología}

La metodología utilizada se basó en métodos estandarizados que incluye la colección, herborización, identificación y recopilación de 
información sobre el nombre común de cada especie en la respectiva zona.

\subsubsection{Recolección}

De acuerdo al plan de acciones y cronograma del proyecto, se programó salidas de campo a partir del mes de mayo al mes de setiembre del año 2012.

Las colectas se realizaron en campos de cultivo, caminos, laderas, montes ribereños. En el proceso se tuvo cuidado de seleccionar especímenes intactos y completos, principalmente de especies anuales y de algunas herbáceas perennes.

Asimismo, las flores, frutos y las semillas de las especies colectadas se utilizaron para la identificación a través de claves taxonómicas. Se tomaron fotografías "in situ" y se realizó un esquema de la planta.

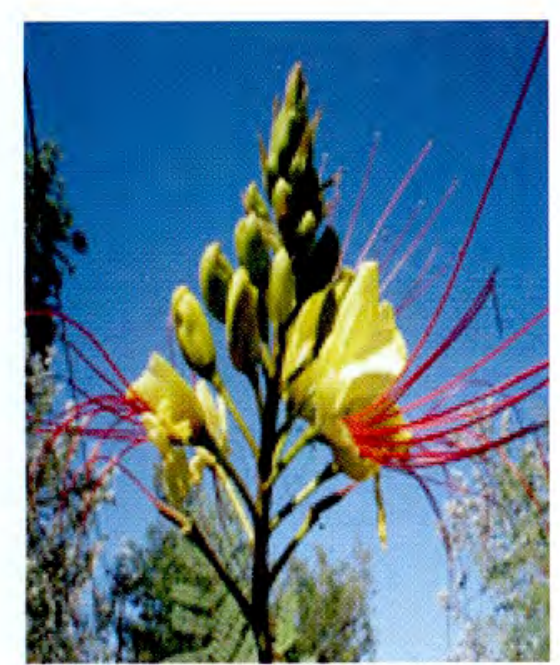

Caesalpinia gilliesiz: "barbas de chivo"

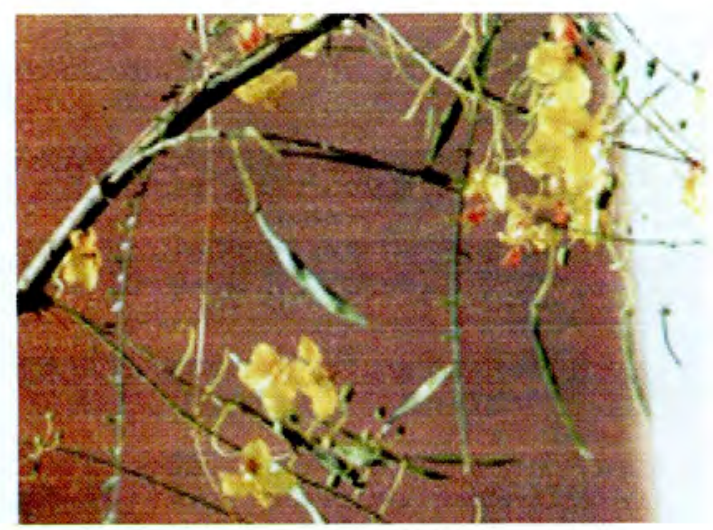

Parkinsonia aculeata L.: "palo verde"

\subsubsection{Prensado}

Una vez identificada la especie en el campo, fueron prensadas y etiquetadas. En las etiquetas se anotaron los datos siguientes: departamento, localidad, hábitat, altura, colector, fecha de recolección, datos taxonómicos: familia, género, especie, nombre científico y nombre vulgar.

\subsubsection{Identificación}

La identificación de especies se basó en revisión de ejemplares de herbario, consulta bibliográfica y mediante juicio de expertos.

\section{III.- RESULTADOS}

\subsection{Especies identificadas}

Se identificaron las siguientes especies:

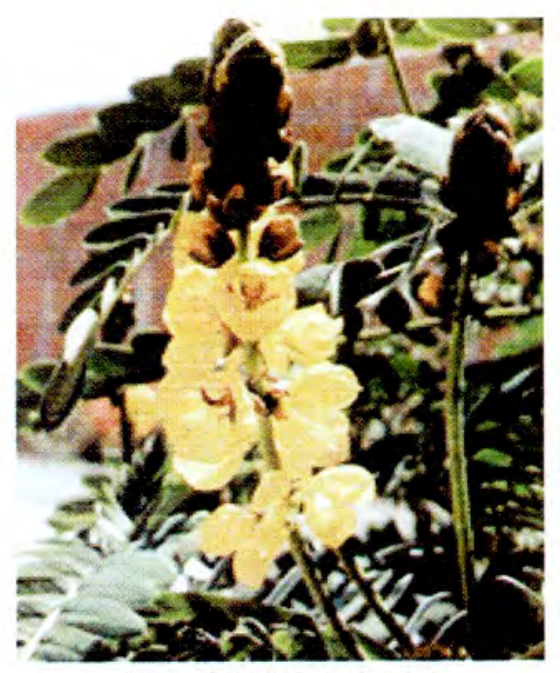

Senna birostris: "mutuy"

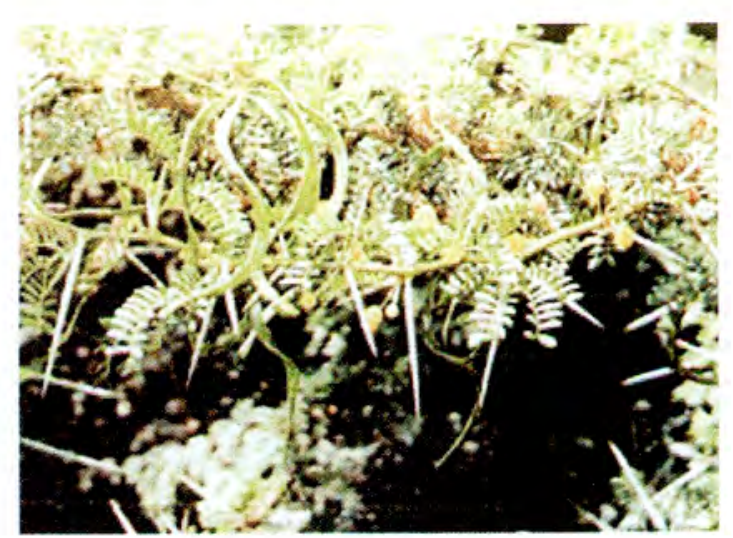

Acacia macrantha: "huarango" Inga feuillei: "pacae" 


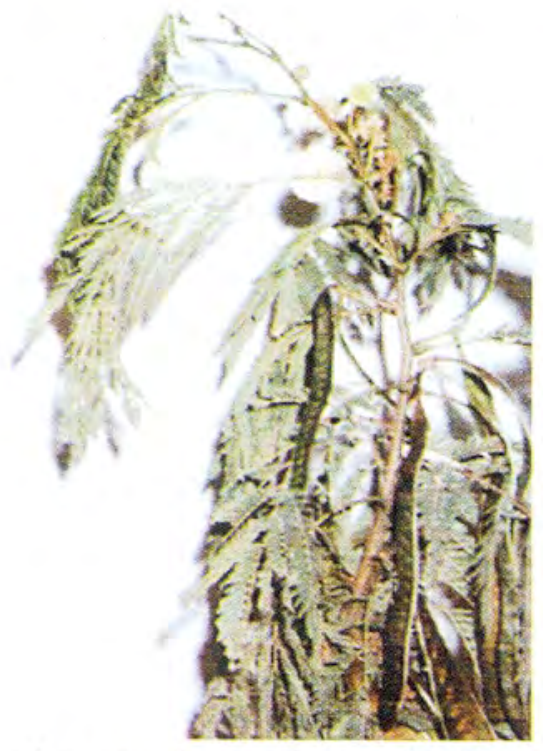

Leucaena leucocephala: "vilquilla"



Medicago sativa "alfalfa"

Medicago polymorpha L. "trébol" Medicago lupulina "trébol"



Pisum sativum: "arveja" Trifolium repens: "trébol"

Vicia faba "haba"
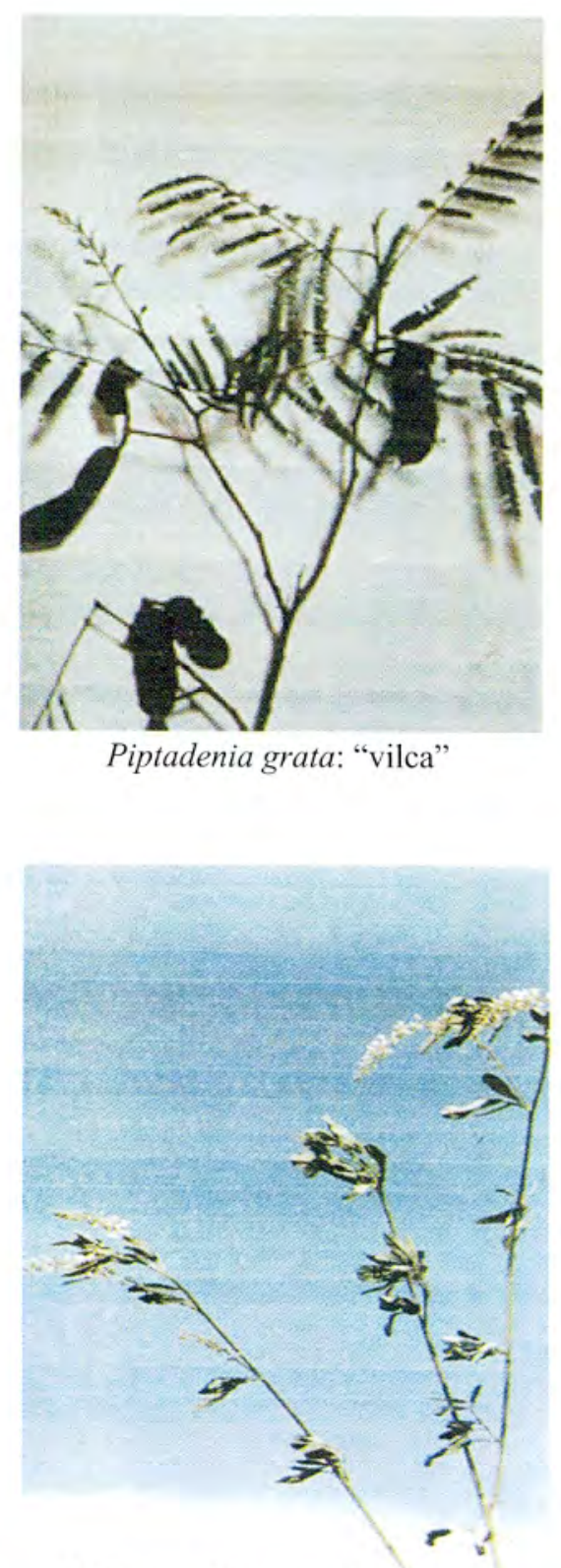

Melilotus albus: "trébol blanco"

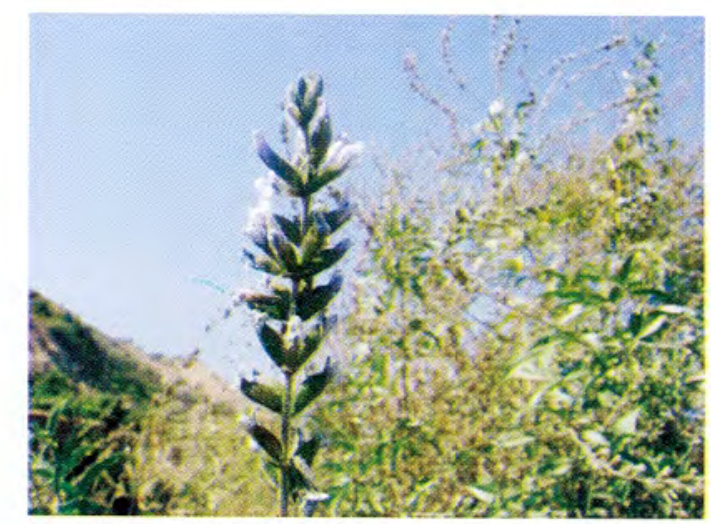

Otholobium pubescens: "culén" 

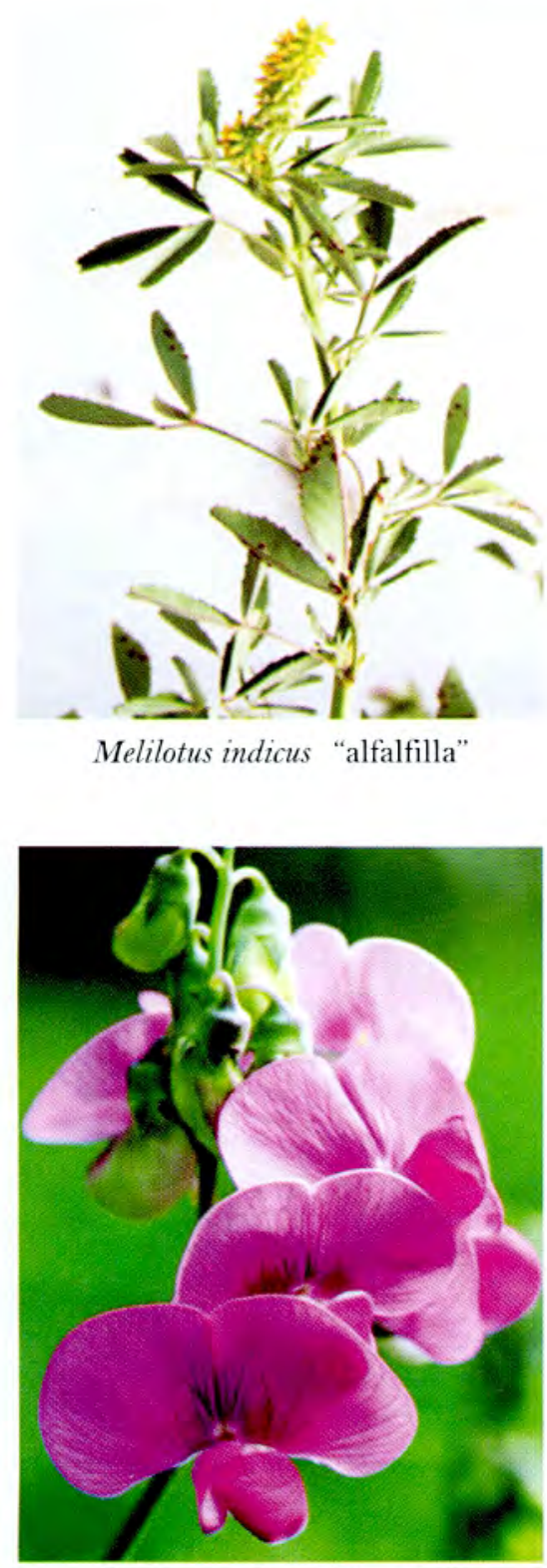

Lathyrus adoratus: "pavito"

\subsection{Sistemática de las especies identificadas}

División : Dicotyledoneae

Subclase :Archichlamydeae

Orden : Rosales

Familia : Fabaceae

\section{Sub-familia: Caesalpinoideae}

Género : Caesalpinia

Especie : Caesalpinia gilliesil

Nombre común: Barbas de chivo

Género : Senna

Especie : Sennabirostris

Nombre común: Mutuy

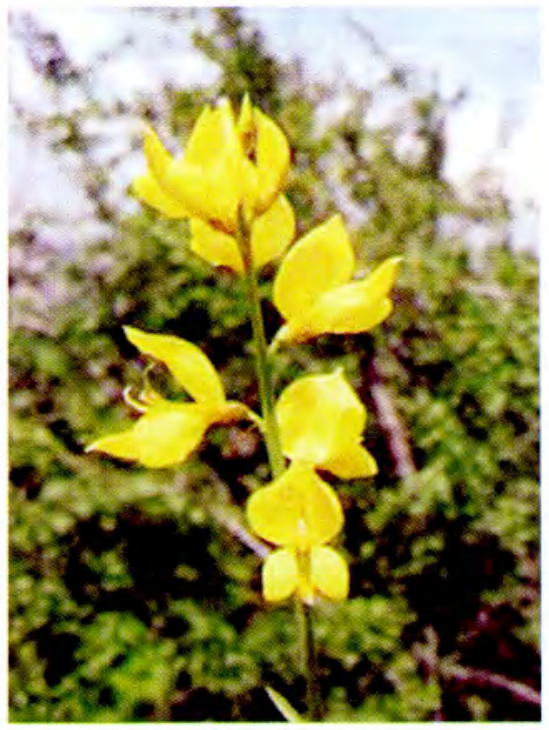

Spartium junceum: "retama"

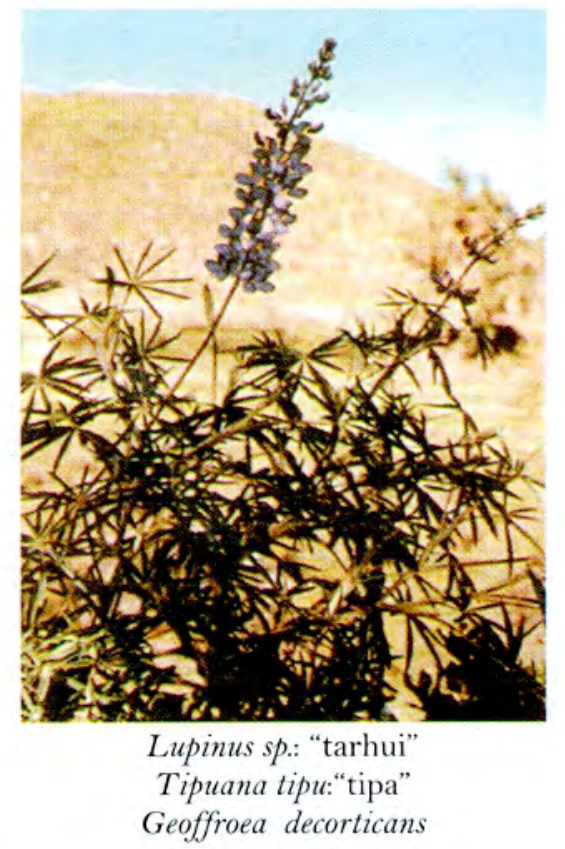

Género : Parkinsonia

Especie : Parkinsoniaaculeata L.

Nombre común: Palo verde

\section{Sub-familia : Mimosoideae}

Género : Acacia

Especie : Acaciamacrantha

Nombre común: huarango

Género : Inga

Especie :Ingafeuillei

Nombre común: pacae

Género : Leucaena

Especie :Leucaenaleucocephala

Nombre común: Vilquilla 
Género : Piptadenia

Especie : Piptadeniagrata

Nombre común: Vilca

\section{Sub-familia: Faboideae}

\section{- Género: Medicago}

Especie : Medicagosativa

Nombre común: alfalfa

Especie :Medicagopolymorpha

Nombre común: Trébol

Especie : Medicagolupulina

Nombre común: Trébol

\section{- Género: Melilotus}

Especie : Melilotus albus

Nombre común: Trébol blanco

Especie :Melilotus indica

Nombre común: alfalfilla

\section{- Género: Pisum}

Especie :Pisum sativum

Nombre común: arveja

\section{- Género: Trifolium}

Especie :Trifolium repens

Nombre común: Trébol

\section{- Género: Vicia}

Especie : Viciafaba

Nombre común: haba

\section{- Género: Spartium}

Especie: Spartium junceum

Nombre común: retama

\section{-Género: Otholobium}

Especie: Otholobium pubescens

Nombre común: coba, culén

\section{- Género: Lathyrus}

Especie: Lathyrus adoratus

Nombre común: Pavito

-Género: Lupinus

Especie: Lupinus sp.

Nombre común: Tarhui

\section{-Género: Tipuana}

Especie: Tipuana tipu

Nombre común: Tipa

\section{- Género: Geoffroea}

Especie: Geoffroea decorticans

\subsection{Características botánicas de especies identificadas}

\section{Caesalpinia gilliesii: "barbas de chivo"}

Arbusto glanduloso, oriundo de América del Sur (Argentina).

Hojas: compuestas, de 10 a $16 \mathrm{~cm}$ de longitud.

Inflorescencia: en racimo.

Flores: con pétalos tenues, de color amarillo claro

Androceo: 10 estambres de color rojo

Gineceo: con estilos exertos de color rojo

Fruto: legumbre comprimida, seca

\section{Senna birostris: "mutuy"}

Arbusto de 1 a $2 \mathrm{~m}$. de longitud, tallo piloso

Hojas: pinnadas, peciolo y raquis a menudo con glándulas gruesas en la cara superior

Flores: solitarias o en racimo, axilares o laterales. Corola: 5 pétalos y cáliz : 5 sépalos imbricados

Androceo: 10 estambres

Ovario: de color blanco, piloso

Fruto: vaina indehiscente

\section{Parkinsonia aculeata L.: "palo verde"}

Planta arbórea, espinosa, de copa ancha, tronco y ramas de color verde

Hojas: compuestas con estípulas espinosas.

Foliolos distanciados

Flores: agrupadas en racimos

Corola. Con pétalos de color amarillo

Fruto: legumbre o vainas con 1 a 15 semillas

\section{Acacia macrantha: "huarango"}

Arbusto perenne provisto de espinas

Hojas: bipinnaticompuestas

Flores: pequeñas, actinomorfas, corola de pre floración valvar, estambres numerosos (más de 10)

Fruto: es un lomento, con 5 a 6 semillas.

\section{Inga feuillei: "Pacae"}

Plantas arbóreas

Hojas: pinnaticompuestas con el peciolo y raquis alados

Flores: actinomorfas, con pétalos diminutos, en general número de 4 a 5 .Lo que da vistosidad a las flores, no es la corola sino el androceo que está compuesto por numerosos estambres de largos filamentos exertos y por lo común de c olor amarillo

Fruto: indehiscente y con cierta cantidad de pulpa blanca

\section{Leucaena leucocephala: "vilquilla"}

Árbol de 1 a 1,50 m de alto

Hojas: con peciolo de más de $10 \mathrm{~cm}$ de longitud, 
con algunas glándulas

Inflorescencia: en cabezuela, flores de color amarillo

Fruto: vainas de 14 a $20 \mathrm{~cm}$ de longitud por $1,5 \mathrm{a}$ $2 \mathrm{~cm}$ de ancho con numerosas semillas.

\section{Piptadenia grata: "vilca"}

Planta arbórea de copa extendida

Hojas: compuestas, grandes, bipinnadas, foliolos numerosos

Inflorescencia: en capítulos redondos, con flores pequeñas, pétalos amarillos y estambres exertos

Fruto: en legumbre comprimida, coriácea, seca

\section{Medicago sativa: "alfalfa"}

Conocida como la "Reina de las plantas forrajeras" es indudablemente la más notable entre la planta forrajera y universalmente reconocida como una de las, más nutritivas y adaptadas a la alimentación de todas las especies animales, en particular para el ganado vacuno.

Hierbas erectas, perennes,

Hojas: alternas, pinnadas, trifoliadas, foliolos ovales, cuneiformes, dentados en el ápice, estípulas lanceoladas

Flores: hermafroditas de color azul, agrupadas en racimos cortos e incluso aislados, cáliz acampanado con cinco dientes casi iguales y corola papilionácea

Androceo: con estambres diadelfos

Fruto: legumbre

\section{Medicago polymorpha L.: "trébol"}

Hierba anual postrada. Hojas trifoliadas, denticulados hacia el ápice, pinnatinervios, con nervaduras secundarias paralelas, con estípulas Flores amarillas de 4-5 mm de longitud, en racimos axilares y solitarios.

Cáliz: en forma de campana con cinco dientes iguales

Corola: papilionácea, amarilla, 10 estambres diadelfos, gineceo glabro.

Fruto: legumbre

\section{Medicago lupulina L.: "trébol"}

Hierba perenne, postrada o ascendente, de hasta $40 \mathrm{~cm}$ de longitud. Tallos pubescentes

Hojas: alternas, pinnadas

Flores: pequeñas y de color amarillo; flores dispuestas en racimos axilares.

Estambres: en número de 10, diadelfos

Fruto: vaina reniforme

\section{Melilotus albus: "trébol blanco"}

Hierba robusta, anual o bianual, de 1 a $2 \mathrm{~m}$ de alto.

Hojas: glaucas y de color verde.
Flores de color blanco

Fruto: vaina con una semilla raramente dos

12. Melilotus indica (L): “Trébol de color amarillo"

Hierba anual, hasta $0,80 \mathrm{~m}$ de altura. Glabra

Tallo: cilíndrico, ramificado

Hojas: alternas, pecioladas, trifoliadas

Flores: pequeñas de $2-2,5 \mathrm{~mm}$ de largo, dispuestas en racimo

Corola: amarilla, papilionada. Estambres: 10

diadelfos

Fruto: vaina ovoidea

\section{Pisum sativum: "arveja”}

Planta herbácea, cultivada por sus vainas verdes y sus semillas alimenticias

Hojas: compuestas de 2 a 3 pares de foliolos y el foliolo terminal es impar y termina en zarcillo

Androceo: 10 estambres diadelfos

Fruto: legumbre dehiscente

\section{Trifolium repens: "trébol"}

Hierba perenne, de tallos delgados

Hojas: alternas, 3 - foliolos, con una mancha blanquecina en forma de "V" en el haz

Flores: de color blanco o blanco-rosadas, de 6 a $12 \mathrm{~mm}$ de longitud

Estambres: en número 10, diadelfos

\section{Vicia faba: "habas"}

Planta herbácea, anual, de tallo grueso y lampiño que alcanza casi $1 \mathrm{~m}$ de altura, con foliolos enteros y estípulas más pequeñas que los foliolos

Flores: axilares y corola blanca con manchas negras en las alas

Estambres: diadelfos

Fruto: legumbre, con tres a cuatro semillas.

\section{Spartium junceum: "retama"}

Arbusto de 1 a $3 \mathrm{~m}$ de longitud

Hojas: pequeñas, caducas y unifoliadas

Flores: amarillas, en racimos terminales de 10 a $20 \mathrm{~cm}$ de longitud

Estambres: monodelfos

Fruto: vaina dehiscente, linear.

17. Otholobium pubescens: "culén" "huallhua" Arbusto de 2 a $2,5 \mathrm{~m}$. de longitud, tallos jóvenes pubescentes. Tallos viejos llegan a ser glabros. Corteza gris algo escamosa

Hojas trifoliadas de 6 a $7 \mathrm{~cm}$ de longitud. Foliolo terminal más largo que los laterales.

Flores en racimo axilares con pedicelos cortos de color azul, estambres en número de 10 (diadelfos).

Fruto: legumbre, poco conocida. 
18. Lathyrus odoratus: "pavito"

Especie de jardín que se cultiva como planta ornamental herbácea

Hojas: con uno o dos pares de foliolos y zarcillos, estípulas ovales

Flores: hermafroditas de colores variados, en racimos sostenidas por pedúnculos largos, axilares

Estambres: diadelfos

Fruto: legumbre, recto, glabro

\section{Lupinus sp.: "tarhui"}

Arbusto ligeramente pubescente

Hojas: alternas, pubescentes en el haz y envés

Inflorescencia: en racimo terminal con flores azules, cáliz pubescente

Androceo: con 10 estambres

Fruto: legumbre de cinco a siete $\mathrm{cm}$ de longitud

\section{Tipuana tipu: "tipa”}

Árbol de copa redonda,. Caducifolio

Hojas: compuestas con 6 a 1 pares de foliolos

Flores reunidas en racimos, corola con pétalos de color amarillo, anaranjado, con estrías rojas Fruto: sámara

\section{Geoffroea decorticans: "chañar"}

Árbol o arbusto de corteza verdosa y caediza con placas longitudinales

Hojas: compuestas pinnadas

Flores: de color amarillo- anaranjadas

Fruto: es una drupa: El fruto, la corteza, la flor $\mathrm{y}$ las hojas tienen propiedades curativas.

\section{IV.-DISCUSIÓN}

El Perú tiene una larga y notable historia botánica, desde el siglo XVIII, hasta la fecha. En la actualidad son muchos los científicos peruanos y extranjeros que se dedican a la colección de plantas en las diferentes regiones de nuestro país; sin embargo, hasta la fecha, no se ha completado la publicación de varias familias botánicas (Brako \& Zarucchi, 1993).

De acuerdo con el Plan Director de estrategias del Sistema Nacional de Áreas protegidas del Perú (INRENA, 1995), la cordillera meridional de los Andes Occidentales, que incluye grandes regiones de los departamentos de Arequipa, Moquegua y Tacna, es un área con vacío de información y de prioridad 1 , lo que significa que no se tiene información acerca de su diversidad biológica. La diversidad biológica del departamento de Moquegua ha sido poco estudiada, a pesar de ser conocida la importancia y urgencia de este tipo de trabajos con propósitos de
conservación(Ferreyra, 1961; Rodríguez, 1996).

El estudio de especies de la familia Fabaceae en el distrito de Torata, ubicado en la provincia Mariscal Nieto, a $25 \mathrm{~km}$ de la ciudad de Moquegua, se realizó durante los meses de abril a diciembre del 2012. Se hicieron colectas en campos de cultivo, caminos, laderas y montes ribereños de la zona de estudio, habiéndose colectado 21 especies de fabáceas, incluidas en 18 géneros y 3 sub-familias, correspondiendo 3 especies a la sub-familia Caesalpinoideae, 4 a la sub familia Mimosoideae y 14 especies a la sub-familia Faboideae.

La determinación de ejemplos y especies se hicieron basándonos en las características botánicas como hojas, flores y frutos, así mismo utilizando claves taxonómicas, juicio de expertos y especialistas del Herbario de la Universidad Nacional de Trujillo.

Brako y Zarucchi (1993) en su catálogo de Plantas con flores y Gimnospermas del Perú menciona la presencia de 138 géneros y 971 especies de la Familia Fabaceae en el sur del Perú; en éste trabajo de investigación se realizó colectas a 2207 m.s.n.m. reportando 21 especies durante los meses de abril a diciembre del año 2012 .

Las especies estudiadas tienen importancia en la vida cotidiana de los pobladores como Spartium junceum, Medicago sativa, Otholobium pubescens, Geoffroea decorticans, mientras que las especies cultivadas por su alto poder nutritivo en proteínas es Vicia faba y Pisum sativum y son especies forrajeras Medicago sativa, Trifolium repens, Melilotus indica.

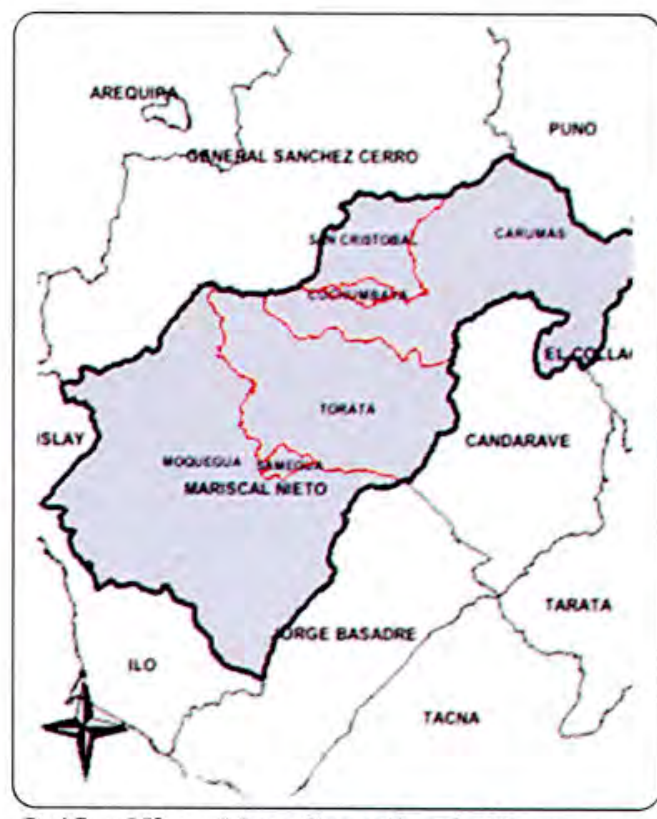

Gráfico $\mathrm{N}^{\circ}$ 02. Mapa Geográfico de Moguegua. 


\section{V.- CONCLUSIONES}

- En la zona de estudio se determinó 21 especies de Fabaceas, pertenecientes a 18 géneros y 3 sub-familias, en un piso altitudinal de 2207 m.s.n.m.

- Se reporta especies de las tres sub-familias Caesalpinoideae, Mimosoideae y Faboideae, destacando la sub-familia Faboideae con 14 especies.

- Las Fabaceas existentes en la zona son usadas por los pobladores como alimento, otras tienen uso medicinal y otras son forrajeras.

\section{REFERENCIAS BIBLIOGRÁFICAS}

[1] ARAKAKI M. \& CANO A. (2001). Composición florística de la cuenca del Río Ilo-Moquegua y Lomas de Ilo, Perú. Rev Per Biol 10(1): 5-19. Facultad de Ciencias Biológicas de la Universidad Nacional Mayor de San Marcos.

[2] BRAKO Z. \& ZARUCCHI (1991). Catalogue of the Flowering Plants and Gymnosperms of Perú. Monografs in Systematica Botany the Missouri Botanical garden.
[3] BRUNO H.J. (1990). Leguminosas Alimenticias. Lima, Perú: FAEDE.

[4] HAYWOOD V. (1990). Las plantas con flores. España: Reverté

[5] MOSTACERos J. \& MEJÍA F. (1993). Taxonomía de Fanerógamas Peruanas. CONCYTEC. Lima, Perú.

[6] SAGÁSTEGUI A. (1993). Flora invasora de los cultivos del Perú. $1^{\text {a }}$ ed. Trujillo, Perú.

[7] SAGÁStegui A. \& DILlON M. (1990). Diversidad florística del Norte del Perú. $1^{\mathrm{a}}$ ed. Trujillo, Perú: UPAO.

\section{Correspondencia:}

Rosa Amelia Caffo Marruffo rcaffom@unjbg.edu.pe Ciudad Universitaria fundo "Los Granados" Av. Miraflores s/n Tacna - Peru
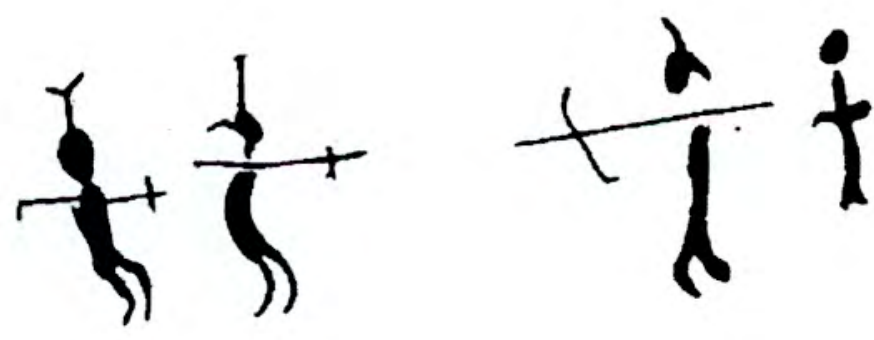